\title{
DIREITO À ALIMENTAÇÃO E O PROTOCOLO DE NAGOYA
}

\author{
RIGHT TO FOOD AND THE NAGOYA PROTOCOL
}

\author{
${ }^{1}$ Romina Ysabel Bazán Barba \\ ${ }^{2}$ Nivaldo dos Santos
}

\section{RESUMO}

Aborda-se, dentro do Direito Ambiental, pela vertente jurídico-sociológica, a problemática do Direito à Alimentação, que, vem sendo intensificada pela falta de equidade, justiça social e principalmente pela degradação ambiental. Com base na dedução da pesquisa teórica, estudase o problema da fome, frente à Constituição e aos tratados internacionais sobre o tema, com ênfase ao Protocolo de Nagoya - novo instrumento internacional de acesso e repartição dos recursos genéticos. Objetiva-se analisar a geopolítica por trás da fome; o uso indiscriminado de agrotóxicos; o monopólio das sementes; e, todas as vidas que são desperdiçadas nesse processo de manutenção e circulação do mercado alimentício.

Palavras-chave: Direito Ambiental; Direito à Alimentação; Fome; Sementes; Protocolo de Nagoya.

\begin{abstract}
In the perspective of Environmental Law, the juridical-sociological aspect addresses the problem for the Right to Food, which has been intensified by the lack of equity, social justice and mainly by environmental degradation. Based on theoretical research, the Constitution and international treaties on the subject, the problem of hunger is studied, with emphasis on the Nagoya Protocol - a new international instrument for access and distribution of genetic resources. It aims to analyze the geopolitics behind the hunger issue; the indiscriminate use of agrochemicals; the monopoly of seeds; and the lives wasted in the process of maintenance/circulation in the food market.
\end{abstract}

Keywords: Environmental Law; Right to Food; Hunger; Seeds; Nagoya Protocol.

\footnotetext{
${ }^{1}$ Mestranda em Direito Agrário pela Universidade Federal de Goiás - UFG, (Brasil). Advogada. E-mail: rominabazan92@gmail.com (Canadense)

${ }^{2}$ Doutor em Direito pela Pontifícia Universidade Católica - PUC, São Paulo, (Brasil). Professor Titular da Pontifícia Universidade Católica, e da Universidade Federal de Goiás, UFG. E-mail:

nivaldodossantos@bol.com.br
} 


\section{INTRODUÇÃO}

A problemática do Direito à Alimentação se insere num contexto socioambiental, no qual a promoção do desenvolvimento deve respeitar mais do que simplesmente a sustentabilidade ambiental, mas incluir também a sustentabilidade social - reduzindo a fome, a miséria e as desigualdades - promovendo equidade e justiça social.

Dessa forma, ao se propor o estudo do Direito à Alimentação dentro do macro tema do Direito Ambiental, o problema da fome no contexto mundial não pode deixar de ser analisado, seguindo-se sempre pela tradição daqueles que primeiro apontaram estes problemas, buscando alternativas para tornar a vida neste mundo o mais duradoura possível. Autores como Jean Ziegler, Rachel Carson, Pat Roy Mooney e Josué de Castro serão nortes para análise em um primeiro ponto do presente artigo.

Em meio a tantas questões ambientais e socioambientais que colocam em debate a justiça social, a paz e a democracia, discute-se a questão envolvendo as sementes, que são um instituto de liberdade ao se observar todos os esquemas de manipulação das mesmas. A proteção das sementes numa sociedade sustentável garante a manutenção da vida das presentes e futuras gerações.

Posteriormente, já adentrando propriamente na temática do Direito à Alimentação, após traçado o panorama de toda a geopolítica que envolve a fome, o uso dos agrotóxicos e os monopólios sobre as sementes, discute-se esse direito como uma questão de soberania de cada país sobre a alimentação de sua população e como dever dentro de um Estado democrático.

Porém, como se irá demostrar esse direito parte de toda uma construção social para ser efetivado. Além dos problemas que envolvem os alimentos, tem-se como foco os problemas ambientais, visto que, sem um ambiente saudável é impossível garantir algum direito alimentar aos cidadãos de todo o globo.

Nesse sentido, inúmeros instrumentos internacionais são criados para amparar e proteger o meio ambiente, como uma forma de aliança global para garantir um futuro para todos. Dentre eles, um instrumento de extrema importância é a Convenção sobre Diversidade Biológica (CDB), que visa primordialmente à conservação de toda a biodiversidade existente, através do uso sustentável dos recursos naturais e pela justa e equitativa distribuição dos benefícios desse uso.

O mais recente documento internacional em vigor desde 2014, que vem para garantir, amparar e efetivar a CDB, é o Protocolo de Nagoya, assim chamado por ter sido criado na 
cidade de Nagoya, no Japão. Este documento, dentre os vários pontos positivos, destaca-se que reconhece a importância dos recursos naturais para a segurança alimentar, bem como respeita a soberania de cada Estado e traz maior segurança para as transações internacionais de intercambio de recursos genéticos.

Ao analisar este relevante instrumento que o Brasil precisa ratificar, tem-se inúmeras conexões que serão feitas no último ponto com o chamado Direito à Alimentação, de forma que este documento viria a garantir ainda mais esse direito, além do amparo ao meio ambiente e as questões agrárias. Assim, nota-se a importância da proposta de estudo do presente artigo, uma vez que, o problema ainda é realidade tanto no contexto mundial como olhando apenas para o Brasil.

Com vistas às peculiaridades do tema proposto, a metodologia dá-se com base nas autoras Gustin e Dias (2010, p. 22-25 e 86), tendo este artigo uma perspectiva interdisciplinar - passando por diversos campos de conhecimento, guiando-se pela vertente jurídicosociológica, na qual se compreendem os problemas em um meio social amplo, discutindo a relação entre direito e sociedade. Empregaram-se os métodos de raciocínio dedutivo - na pesquisa teórica; indutivo - na observação de instrumentos internacionais, principalmente o Protocolo de Nagoya; e, dialético - levantando-se os pros e contras da questão.

\section{O PROBLEMA DA FOME}

O maior escândalo desta Era é ainda se ter, mesmo com toda a chamada "modernidade", leis e tantas tecnologias novas, milhares e milhares de pessoas mortas a cada ano vítimas da miséria chamada fome. As tremendas desigualdades sociais mitigadas pelos governos e autoridades são muito presentes e estão mais próximas do que se pode imaginar. O problema está em que a agricultura de todo o mundo têm sim capacidade para suprir a população mundial, porém a desigualdade assassina pessoas diariamente através da fome.

A indiferença ou até mesmo o desconhecimento da sociedade como um todo sobre essa "destruição em massa" - como chama Jean Ziegler ${ }^{3}$ - é o mais chocante. Apenas quando ocorrem catástrofes de grande escala é que o problema se torna "visível" ou importante para a sociedade. O problema da fome também inclui a desnutrição e a subnutrição, bem como todos os problemas adjacentes da má alimentação para a saúde humana.

\footnotetext{
${ }^{3}$ Humanista suíço contemporâneo que estuda a fome. Admirado em todo o mundo pela dedicação com que realiza
} seus trabalhos. (ZIEGLER, 2013, p. 11). 
Ziegler (2013, p. 31-36) aponta em sua obra que o Direito à Alimentação é o Direito Humano mais violado em todo o mundo e em dados, traz que cerca de um bilhão dos 6,7 bilhões de seres humanos padecem de fome. A FAO (Organização das Nações Unidas para a Alimentação e a Agricultura) é a responsável pelos dados referentes à fome, porém a maneira como realiza suas estatísticas acaba deixando de lado a má alimentação, pois calcula a quantidade de calorias por habitantes em cada país, porém sem analisar seu valor nutricional. A morte pela fome não é rápida como se pode pensar, mas se dá em cinco estágios agoniantes e a subalimentação em menores de cinco anos de idade gera lesões irreversíveis, mesmo que posteriormente sejam bem alimentadas.

Outro ponto relevante ao se estudar à geográfica da fome é entender a diferença da denominada "fome estrutural" (por produção insuficiente) da "fome conjuntural" (por catástrofe natural ou guerra). Ziegler (2013, p. 39-53) destaca que os mais expostos á fome são as populações rurais mais pobres, que também são vítimas de muita violência. Como também, o preconceito sobre as mulheres ainda é presente, sendo que em alguns lugares - como na Ásia e África - as mulheres comem os restos de alimentos dos homens. A estatística que o autor traz é que no mínimo um ser humano a cada sete sofre as consequências dessa geografia da fome, que sempre destrói os mais fracos e pobres.

Nesse sentido, vale lembrar os pensamentos do grande sociólogo Zygmunt Bauman em sua obra "Vidas Desperdiçadas" (2005), que trata da figura do "refugo" humano, ou seja, o excedente que precisa ser excluído como lixo. Na política da fome, tem-se que a modernização em âmbito mundial por meio da comercialização, mercantilização e agregação de valor monetário a todos os meios de subsistência, torna cada vez mais necessária essa "limpeza", para deixar mais "espaço" para os que podem contribuir nesse processo de modernização ${ }^{4}$, marginalizando e excluindo todos os que não se enquadram nela.

Ziegler (2013, p. 103) nessa mesma esteira de raciocínio cita Thomas Malthus com a ideia da "seleção natural" e também a "lei da necessidade", que se funda na tese de que a população é crescente enquanto que a terra é limitada, assim a fome reduz a população para trazer um "equilíbrio". É claro que todos esses pensamentos que naturalizam a fome e tiram todo senso de moral são errôneos e totalmente desumanos, visto que a fome como bem demostra

\footnotetext{
${ }^{4}$ Bauman (2001, p. 7-22) criou o conceito de "Modernidade líquida" e possui uma obra específica para esse tema, na qual trata das rápidas transformações que o ser humano precisa enfrentar na busca por afirmação dentro de uma sociedade competitiva, desigual e rodeada de incertezas.
} 
Ziegler não é produto de uma superlotação da terra ou falta de suprimentos e sim de uma má distribuição.

Seguindo essa linha de raciocínio, o autor trata do problema das crises prolongadas fome estrutural e conjuntural ao mesmo tempo - carrega a insegurança alimentar, e sempre são enfrentadas por países subdesenvolvidos (como exemplo Níger, Gaza e Coreia do Norte). Para demostrar o quão próxima essa realidade é presente, ele aponta o Nordeste brasileiro, especificamente Crateús-Ceará a tremenda pobreza enfrentada pelos "boias-frias" e a quantidade de crianças mortas pela fome a cada ano. (ZIEGLER, 2013, p. 61-77).

Após a Segunda Guerra Mundial, houve um despertar da consciência mundial, os campos nazistas afrontaram o mundo todo e rompeu-se com o silêncio. Nesse período, surge Josué de Castro ${ }^{5}$, brasileiro de notório conhecimento por sua obra "Geografia da fome" (1984) que ao denunciar a fome teve como principal base de argumentação a noção de justiça, e por tanto esta deve ser combatida por ser injusta.

Nesse sentido, estudou todas as faces da subalimentação e da má nutrição região por região do Brasil, e concluiu que os latifúndios eram a causa original desses males, dando um caráter geopolítico à fome, culpando assim a colonização, a monopolização e a monocultura pela baixa produtividade e injusta distribuição (ZIEGLER, 2013, p. 117-118).

O Programa Alimentar Mundial (PAM) juntamente com a FAO são legados de Josué de Castro, mas na atualidade veem sendo ameaçadas por todos esses jogos de interesses do mercado, que coloca maior importância no lucro, ao invés da alimentação que é um Direito Humano e universal.

Ao se falar da fome não se pode deixar de lado o problema envolvendo os agrotóxicos e, com relação a eles a autora Rachel Carson (2010) discute que as novas tecnologias não acompanharam o senso de moral da humanidade e a poluição por produtos químicos era um fruto de pura ignorância e cobiça humana. Com sua obra "Primavera Silenciosa", ela ganhou fama demostrando que a saúde humana é apenas um espelho dos males ambientais, sendo ambas inseparáveis.

\footnotetext{
${ }^{5}$ Médico, que entendeu logo cedo que a fome estava presente na vida de grande parte da população brasileira e dedicou toda sua vida para chamar a atenção ao problema da fome e da miséria que assolavam o Brasil e o mundo. Como também se preocupou em estudar as questões de interesse global relacionadas, como o meio ambiente e o subdesenvolvimento. Foi também professor, político, escritor e ativista que ocupou cargo de Presidente do Conselho Executivo da Organização das nações Unidas para Agricultura e Alimentação (FAO) e também Embaixador brasileiro na Organização das nações Unidas (ONU). (ZIEGLER, 2013, p. 112-115).
} 
Os agrotóxicos representam um dos mais graves problemas de poluição causada por produtos químicos. As suas implicações são muito graves, pois abrangem área que oscila desde a produção de alimentos e da sua qualidade até a saúde humana afetada, seja pelos próprios agrotóxicos, seja pelo consumo de alimentos contaminados. (ANTUNES, 2015, p. 1067, grifo nosso).

Rachel Carson (2010, p. 24 e ss) aponta à época como principal exemplo o DDT e os demais "biocidas" assim por ela denominados, pois não matam apenas uma determinada espécie de "praga" mais atinge o meio ambiente como um todo. O ser humano tem o direito de saber as consequências que terá de suportar com o uso desses produtos, pois contaminam todo o planeta e geram espécies cada vez mais fortes e resistentes. Sendo as alternativas de controle biológico - usando a natureza para controlar a própria natureza - sempre mais benéficas.

\begin{abstract}
A onda atual em favor dos venenos falhou completamente em levar em conta essas considerações mais fundamentais. Como uma arma tão tosca quanto o porrete do homem das cavernas, tem-se lançado um bombardeio de produtos químicos contra o tecido da vida - um tecido, por um lado, delicado e destrutível e, por outro, milagrosamente tenaz e resistente, e capaz de contra-atacar de formas inesperadas. Essas capacidades extraordinárias da vida têm sido ignoradas pelos defensores do controle químico que não agregaram à sua tarefa uma "nobreza de espírito", uma humildade diante das vastas forças com as quais eles interferem (CARSON, 2010, p. 249).
\end{abstract}

Por último, não se pode deixar de lado mais um problema para a fome, o monopólio das sementes. Para Shiva (2001, p. 9), as sementes possuem uma multiplicidade de características, elas são ao mesmo tempo entidades biológicas, sistemas ecológicos e podem também ser desenvolvidas pelo homem. Mas, sua maior e melhor característica é ser um recurso regenerativo, o que denota a sustentabilidade intrínseca a ela. Modernamente, as sementes se tornaram apenas um objeto de mercadoria, tirando-lhe a capacidade regenerativa, seja por serem agora híbridas ou por serem transgênicas, mas patenteadas, não podendo mais ser usado o fruto para uma nova plantação.

Com isso, levanta-se o problema de que a Revolução Verde - RV - criada com base no discurso de acabar com a fome, gerou sim uma alta produção de alimentos, porém a falta de distribuição e equidade faz com que a fome permaneça e ainda haja em larga escala o desperdício de alimentos.

Isto, sem contar que a RV acarretou na “[...] extinção da agricultura tradicional de pequena escala, à perda do conhecimento que a informa, e provocou deslocamentos sociais, os quais por sua vez deram origem à fome e à violência [...] meio ambiente se degradou, houve perda da biodiversidade [...]" (LACEY e OLIVEIRA in SHIVA, 2001, p. 12), além dos riscos 
que envolvem a saúde humana com o uso dessas novas sementes, bem como dos pacotes tecnológicos de insumos químicos a elas inerentes.

A mecanização das sementes e de maneira geral da própria agricultura por parte dos grandes monopólios empresariais trazem resultados catastróficos para os seres humanos e para o meio ambiente como um todo.

Dentro desse contexto socioeconômico da RV, a ciência reducionista, segundo Shiva (2001, p. 15) se define por ser apenas um tipo de conhecimento científico, aquele que entende os fenômenos de maneira a observar unicamente as "estruturas subjacentes e componentes moleculares", os processos, interações e as leis que os regem. Porém, desconsidera as "relações com a vida e a experiência humanas, bem como de suas relações sociais e econômicas", tendo assim a RV seu fim em si mesma, ou seja, o problema não está no que ela inclui, mas no que deixa de lado.

A RV, a partir de 1960, também chamada de "modernização da agricultura", tendo por conceito o método de capitalizar o campo, com as monoculturas e o extermínio da biodiversidade, com grandes máquinas e colocar na prática o tripé capitalista de tempo, custo e lucro.

Essa revolução ficou marcada pelo massivo implemento das sementes modificadas, produtos químicos e financiamento estatal para os que se seguissem por esses moldes. A segunda fase da RV está em processo, por meio da expansão das multinacionais com o domínio da produção e comércio das sementes, controlando assim todo o sistema alimentar e por consequência lógica o sistema político. (MACHADO 2014, p. 51 e ss).

A erosão genética dada pela uniformização e pela vulnerabilidade gerada nas culturas por meio de uma padronização das sementes - produzindo alimentos de igual sabor, cor e forma. Essa igualdade gerada pelos híbridos interfere diretamente na perda de nutrientes e vitaminas existentes na diversidade das culturas, isso se dá, pois, para poderem ser patenteadas pelas grandes empresas, as sementes necessitam estarem em iguais condições. Mooney (1987, p. 95) trata da tendência "PUP", que é a produtividade, a uniformidade e o processamento dos alimentos, porém isto tudo se dá em torno do lucro da empresa e não em produzir algo melhor para o consumidor ou para os agricultores. 


\section{O DIREITO À ALIMENTAÇÃO}

O direito a ter uma alimentação adequada é um direito fundamental de toda pessoa humana. Sendo o Direito à Alimentação parte integrante dos Direitos Humanos, previsto expressamente em vários tratados. Destaca-se que "Dentre todos os direitos humanos, o direito à alimentação é, seguramente, o mais constante e mais maciçamente violado em nosso planeta." (Ziegler, 2011, p. 31).

Artigo 25, §1. Toda pessoa tem direito a um padrão de vida capaz de assegurar a si e a sua família saúde e bem-estar, inclusive alimentação, vestuário, habitação, cuidados médicos e os serviços sociais indispensáveis, e direito à segurança em caso de desemprego, doença, invalidez, viuvez, velhice ou outros casos de perda dos meios de subsistência em circunstâncias fora de seu controle. (ONU, 1948. p. 1, grifo nosso).

O padrão de vida digno previsto na Declaração Universal de Direitos Humanos inclui a alimentação. O Pacto Internacional sobre Direitos Econômicos, Sociais e Culturais em seu artigo 11 também dispõe:

1. Os Estados Partes do presente Pacto reconhecem o direito de toda pessoa a um nível de vida adequando para si próprio e sua família, inclusive à alimentação, vestimenta e moradia adequadas, assim como a uma melhoria continua de suas condições de vida. Os Estados Partes tomarão medidas apropriadas para assegurar a consecução desse direito, reconhecendo, nesse sentido, a importância essencial da cooperação internacional fundada no livre consentimento.

2. Os Estados Partes do presente Pacto, reconhecendo o direito fundamental de toda pessoa de estar protegida contra a fome, adotarão, individualmente e mediante cooperação internacional, as medidas, inclusive programas concretos, que se façam necessárias para:

a) Melhorar os métodos de produção, conservação e distribuição de gêneros alimentícios pela plena utilização dos conhecimentos técnicos e científicos, pela difusão de princípios de educação nutricional e pelo aperfeiçoamento ou reforma dos regimes agrários, de maneira que se assegurem a exploração e a utilização mais eficazes dos recursos naturais;

b) Assegurar uma repartição eqüitativa dos recursos alimentícios mundiais em relação às necessidades, levando-se em conta os problemas tanto dos países importadores quanto dos exportadores de gêneros alimentícios. (BRASIL, 1992, p. 1, grifo nosso).

O disposto no artigo 11 do Decreto $\mathrm{n}^{\circ} 591$ de 1992 regula de forma clara e precisa a efetivação do Direito à Alimentação. Dispõe que toda pessoa tem direito a um "nível de vida adequado", no qual a alimentação faz parte; pressupõe o combate a fome, que todos deveriam estar protegidos e resguardados para não passar pela mesma; e, propõe programas tanto para melhorar a questão produtiva de alimentos quanto à questão distributiva e de justa repartição desses recursos. 
É garantido pela Constituição Federal do Brasil de 1988 em seu artigo sexto, como um direito comum a todos:

São direitos sociais a educação, a saúde, a alimentação, o trabalho, a moradia, o transporte, o lazer, a segurança, a previdência social, a proteção à maternidade e à infância, a assistência aos desamparados, na forma desta Constituição. (Redação dada pela Emenda Constitucional n ${ }^{\circ}$ 90, de 2015) (BRASIL, 1988, p. 1, grifo nosso).

Esses direitos baseiam-se nas atuações positivas do Estado, de forma direta ou indireta, para proporcionar melhores condições de vida e igualdade. Como já foi dito, o Direito à Alimentação, como Direito Humano Fundamental, está além da noção de ser apenas o acesso diário à alimentação em quantidade e qualidade adequadas. Este representa o exercício da dignidade da pessoa humana, como também o direito a ter informações adequadas sobre seus direitos. (VALENTE, 2002, p. 17-21).

\begin{abstract}
Ao desnutrido é negado o direito ao corpo, à vida, a fazer a história. Ao faminto não é negado somente o nutriente, como também lhe é negado o acesso ao prazer de comer, de compartilhar refeições com amigos e familiares, de viver seus hábitos e práticas alimentares que vêm sendo criados e recriados por sua cultura e sua história. [...] Ao faminto analfabeto é dificultado o desenvolvimento da capacidade crítica. Fica este, assim, alijado da possibilidade de participar conscientemente do processo de transformação social e, muitas vezes, até mesmo da luta por seus legítimos interesses, transformando-se em massa de manobra para seus dominadores. (VALENTE, 2002, p. 28, grifo nosso).
\end{abstract}

Valente (2002, p. 30 e ss.) discorre que em um país como o Brasil, que ocupa o terceiro lugar em exportação de alimentos é lastimável que ainda assim existam milhões de crianças sofrendo os impactos da desnutrição. Da alimentação do homem decorre uma transformação da natureza em humanidade, pois não se trata apenas de comer, mas de vários aspectos que tornam os seres humanos diferente dos demais animas.

\footnotetext{
Ao comer, portanto, não só satisfazemos nossas necessidades nutricionais, como também nos refazemos, nos construímos e nos potencializamos uns aos outros como seres humanos em nossas dimensões orgânicas, intelectuais, psicológicas e espirituais. (VALENTE, 2002, p. 38, grifo nosso).
}

Assim, para haver qualidade de vida, equidade e justiça o Direito à Alimentação precisa estar garantido como um Direito Humano Fundamental. A existência de uma segurança alimentar e nutricional depende de "uma sociedade organizada, por meio de políticas públicas, 
de responsabilidade do Estado e da sociedade como um todo, pode e deve garantir o Direito à Alimentação aos seus cidadãos". (VALENTE, 2002, p. 40).

No caso do Brasil, a produção e disponibilidade de alimentos em quantidade suficiente não garantem a segurança alimentar da população. Mas, a insegurança alimentar e nutricional ainda atinge grande parte do povo brasileiro, não obstante a produção aumente mais a cada dia. Assim, nota-se que isto se deve ao quadro de desigualdades sociais ainda vividos, oriundos do acumulo extremo de terras, riqueza e renda; do abastecimento insuficiente de alimentos em regiões urbanas e rurais; e, do inadequado controle de qualidade dos alimentos a serem consumidos pela população brasileira.

Mooney (1987, p. 105-109) trata em sua obra da união das empresas de sementes, de produtos químicos e fármacos, gerando assim um controle maciço do mercado de alimentos. Visto que, as sementes híbridas dependem dos produtos químicos (fertilizantes) para serem produtivas e logo os produtos farmacêuticos são uma decorrência da extração desses produtos. Tornando os seres humanos reféns desse domínio da produção de alimentos e fármacos necessários para a sua sobrevivência.

Dessa forma, têm-se como os maiores inimigos do Direito à Alimentação a Organização Mundial do Comércio (OMC), o Fundo Monetário Internacional (FMI) e o Banco Mundial. As duzentas maiores empresas do ramo agroalimentar controlam aproximadamente um quarto dos recursos produtivos do mundo. A Cargill, por exemplo, utilizando-se do recurso do controle vertical de mercados torna-se o mais poderoso comerciante de grãos, minerais e algodão do mundo, com armazéns gigantescos. (ZIEGLER, 2013, p. 151).

Quando a OMC luta pela liberalização total dos fluxos de mercadorias, de patentes, de capitais e de serviços, reforça a concorrência desigual, impossibilitando a competição dos países do Sul. O FMI encarregado de administrar a dívida externa de vários países do chamado "Terceiro Mundo", e também de abrir os mercados do Sul às sociedades transcontinentais privadas de alimentação faz com que no hemisfério sul "o livre-comércio carrega o rosto repugnante da fome e da morte" (ZIEGLER, 2013, p. 174). As potências agroalimentares decidem, todo dia, quem morre e quem vive, pois controlam a produção e o comércio de todos os insumos, fixando assim o preço dos alimentos.

As lutas sociais pela garantia de iguais liberdades para todos é expressão do Direito à Alimentação (ROCHA, 2011, p. 19). A busca pela soberania alimentar de cada Estado está também ligada na inclusão das minorias; na observância dos direitos fundamentais; na participação de todos; na igualdade e na liberdade de cada cidadão. Um direito só pode ser 
legítimo se houver democracia, e por sua vez, a democracia apenas existe se pautada em um direito legítimo. Dessa maneira, a criação tanto da democracia como do direito se dá por meio de avanços e retrocessos, e é algo que esta sempre em processo de construção. (COSTA, 2005, p. 140).

Por essa razão é que a sociedade por meio da participação popular deve buscar a garantia de seus direitos, dentre eles, o aqui em estudo, Direito à Alimentação. Dessa participação ativa da sociedade é que se tem a efetivação da democracia. A autodeterminação cidadã é compreendida como um longo e ininterrupto processo do sistema de direitos fundamentais, criando o princípio da soberania popular. (HABERMAS, 2003, p. 171).

Em um Estado democrático de direito como é o caso do Brasil, existe uma interdependência da esfera pública e da esfera privada, o que trás um equilíbrio necessário nas relações entre o Estado e os indivíduos, nem sempre o interesse público estará sobre o interesse privado, deve haver um processo participativo e igualitário. Assim, precisam-se reconhecer a todos os cidadãos como suficientes e qualificados para participação da cidadania de maneira real. O debate não deve ser realizar só por pessoas com conhecimentos técnicos em determinados temas, mas por aqueles que têm seus direitos mais lesados, pois são os mais qualificados para tornarem efetivos esses direitos. (ROCHA, 2011, p. 50-55).

\section{O DIREITO À ALIMENTAÇÃO NO PROTOCOLO DE NAGOYA}

Os problemas ambientais que estão intrinsecamente ligados na construção e garantia do estudado Direito à Alimentação, serão aqui analisados com maior ênfase. Neste ponto, vale lembrar que desde o marco da Revolução Industrial houve uma mecanização da agricultura, que aos poucos foi se revelando como uma negação da natureza - destruindo a agrodiversidade - através das monoculturas; da expulsão das comunidades tradicionais; do mencionado uso de produtos químicos; e, da degradação natural que desconsidera a vida animal e vegetal (MACHADO, 2014, p. 31).

Dessa maneira, com o atual modelo vivido da Revolução Verde - já mencionado - e do agronegócio, alternativas como a agroecologia são inseridos no debate, com o fim de ter uma produção agrícola que detenha todos os avanços científicos, mas com o fim de produzir alimentos sem venenos e protegendo o meio ambiente. Assim, a agroecologia passa seus objetivos pela ideia da superação da monocultura e de seus efeitos devastadores, como também inclui os pequenos proprietários que são produtores de alimentos limpos. Mas, a implantação 
desse modelo agroecológico requer a construção de um novo paradigma de desenvolvimento e a retirada do existente.

Em âmbito global, outro problema chama a atenção, a apropriação dos ricos recursos genéticos dos países chamados de "Terceiro Mundo", por meio de modificações genéticas para poderem patentear e vender os mesmos produtos a altos preços para os próprios Estados detentores originários daquele recurso. Dessa maneira, a segurança alimentar não mais depende das produções locais, mas sim das produções das corporações hegemônicas. (GONÇALVES, 2004, p. 5).

Nesse sentido, instrumentos internacionais são criados a fim de regular também o uso e intercambio de recursos genéticos entre diversos países, com o objetivo de proteger os Estados detentores originais das matérias primas, assegurando a segurança e soberania alimentar de cada Estado, bem como a proteção da diversidade biológica do planeta. Logo na introdução, a Convenção sobre Diversidade Biológica (CDB) é mencionada com o propósito de analisar-se melhor o Protocolo de Nagoya, dentro da temática do Direito à Alimentação.

Em análise geral o Protocolo de Nagoya trata diretamente do acesso aos recursos genéticos e a repartição de seus benefícios. Em seus trinta e seis artigos, reconhece a soberania dos Estados sobre seus próprios recursos; dispõe sobre a transferência de tecnologias na busca do desenvolvimento sustentável; reconhece a importância dos recursos genéticos na segurança alimentar; e, a proteção dos conhecimentos tradicionais e dos direitos indígenas. Dessa forma, este instrumento trará maior segurança jurídica e transparência para os provedores e usuários de recursos genéticos. Porém, o Brasil ainda não o ratificou o que poderá dificultar ainda mais a proteção de seus recursos.

Analisando especificamente o conteúdo do Protocolo de Nagoya na discussão do Direito alimentar, têm-se logo no Preâmbulo que as partes deste protocolo,

\footnotetext{
Reconhecendo a interdependência de todos os países em relação aos recursos genéticos para alimentação e agricultura, bem como sua natureza especial e sua importância para lograr a segurança alimentar em escala global e para o desenvolvimento sustentável da agricultura no contexto de redução da pobreza e de mudanças climáticas, e reconhecendo o papel fundamental do Tratado Internacional sobre Recursos Fitogenéticos para Alimentação e Agricultura e da Comissão da FAO sobre Recursos Genéticos para Alimentação e Agricultura a respeito. (SECRETARIADO DA CONVENÇÃO SOBRE DIVERSIDADE BIOLÓGICA; MINISTÉRIO DO MEIO AMBIENTE - MMA, 2014, p. 12, grifo nosso).
}

Deste ponto se extrai que a interdependência dos Estados sobre seus próprios recursos é fundamental na manutenção do Direito à Alimentação e na segurança alimentar, visto que não 
seria possível a outros países apossar-se e até mesmo patentear recursos originários de determinado país. A título de exemplo, seria proibido o Japão decodificar a sequência genética de um determinado fruto brasileiro e patenteá-lo como se fosse originário do Japão, pois estaria desrespeitando a soberania do Brasil sobre seus recursos genéticos. Bem como, o protocolo também reconhece a importância de outros tratados que são voltados para a proteção dos recursos fitogenéticos para a alimentação e a Comissão da FAO.

Já adentrando nos artigos especificamente, têm-se no Artigo 08 (oito) algumas considerações especiais, dentre elas destaca-se a letra "c",

Ao desenvolver e implementar sua legislação ou seus regulamentos sobre acesso e repartição de benefícios, cada Parte:

[...]

(c) considerará a importância dos recursos genéticos para a alimentação e agricultura e seu papel especial para a segurança alimentar. (SECRETARIADO DA CONVENÇÃO SOBRE DIVERSIDADE BIOLÓGICA; MINISTÉRIO DO MEIO AMBIENTE - MMA, 2014, p. 18-19, grifo nosso).

Reconhece novamente, dentro do quadro de acesso e repartição dos benefícios, advindo do uso dos recursos genéticos, que no momento em que as Partes forem legislar sobre o tema levem em consideração a importância destes recursos para a alimentação e garantia da segurança alimentar.

O anexo do Protocolo de Nagoya trata dos benefícios monetários e não monetários. Ao analisar os benefícios não monetários destaca-se,

2. Entre os benefícios não monetários podem-se incluir, mas não se limitar a:

$[\ldots]$

(m) pesquisa dirigida a necessidades prioritárias, tais como saúde e segurança alimentar, tomando em conta os usos nacionais de recursos genéticos na Parte provedora de recursos genéticos;

[...]

(o) benefícios em matéria de segurança alimentar e dos meios de subsistência; (SECRETARIADO DA CONVENÇÃO SOBRE DIVERSIDADE BIOLÓGICA; MINISTÉRIO DO MEIO AMBIENTE - MMA, 2014, p. 39-41, grifo nosso).

A repartição justa e equitativa de benefícios que é base tanto da CDB como do Protocolo de Nagoya se dá em valor monetário e não monetário. Dentre aqueles não monetários, mas não menos importantes, previstos no Protocolo de Nagoya estão às mencionadas letras "m" e "o". Na letra " $m$ " se destaca o incentivo a pesquisas dirigidas para a segurança alimentar, colocando-a como uma necessidade prioritária. Já na letra “o” têm-se assegurados os benefícios da segurança alimentar e também dos meios de subsistência. 
Ora, todos esses benefícios estão intrinsecamente ligados à garantia do Direito à Alimentação. Isso, sem contar que, outros objetivos do Protocolo de Nagoya, podem indiretamente interferir beneficamente na manutenção do direito alimentar. A transferência de tecnologias, por exemplo, assegurada no protocolo com todos seus direitos e até com financiamento adequado, é importante para a manutenção de um modelo produtivo na agricultura e consequentemente na produção e exportação de alimentos.

A conservação da diversidade biológica é sem dúvida mais um ponto importante que contribui para o Direito à Alimentação, pois como se observou, a uniformidade dos alimentos implica em perda de valores nutricionais, como minerais e vitaminas essências para a garantia de uma boa alimentação a qualquer ser humano.

Por fim, os conhecimentos tradicionais e os direitos das comunidades indígenas são fundamentais na manutenção do Direito à Alimentação. Muitos dos controles biológicos de "pragas", técnicas de extração e consumo e até mesmo a cura de várias doenças, já são conhecidos há anos por comunidades indígenas, e a proteção destes conhecimentos para cada país é fundamental, pois impede que outros países usem dos conhecimentos nativos para patenteá-los fora. Como também, garante a essas comunidades direito aos benefícios advindos de seus conhecimentos sobre os recursos genéticos.

\section{CONCLUSÃO}

Ante todo o exposto, afirma-se que o problema da fome é ainda muito presente em todas as partes do mundo, e é claro, em especial nos países subdesenvolvidos - assim chamados por vários autores - que acabam se tornando reféns dos países desenvolvidos. Sabe-se que controlando as sementes se controla todo o sistema de alimentos e elas são a chave do potencial de comércio de mercadorias para os países menos desenvolvidos.

Destaca-se que a semente sendo o instrumento de venda de produtos químicos, nada mais óbvio que usar-se disso para vender um "pacote" fechado de sementes mais produtos químicos, deixando o agricultor sem opção, e o consumidor obrigado a suportar seus efeitos.

Compreende-se que para haver uma boa conservação e armazenagem das sementes muito se precisa investir economicamente e se apenas alguns detém essas reservas poder-se-ia ter num futuro o controle político e econômico de todo o resto do mundo.

Dessa forma, os novos donos das sementes são grandes indústrias que se fundem para dominar o mercado, principalmente a junção de três setores, o das sementes, dos produtos 
químicos e das drogas, visto que as drogas derivam das plantas e estas por sua vez estão ligadas aos produtos químicos para serem mais rentáveis. E assim, o fornecimento de sementes melhoradas para os países em desenvolvimento têm feito com que muitas variedades antigas se perdessem.

Aprecia-se que o Direito à Alimentação deve ser garantido a todos e a soberania alimentar está ligada a segurança alimentar de cada Estado. Dessa forma, a efetivação do Direito à Alimentação advém da organização civil e das lutas sociais, que inserem a população nos debates públicos, influenciando o Estado para a concretização de políticas públicas voltadas para a segurança alimentar e nutricional.

Pode-se afirmar que as políticas públicas devem estar norteadas pela justiça distributiva - de Aristóteles, na qual apresenta o Estado como o agente repartidor - e a justiça social - de Santo Tomas de Aquino, que busca o equilíbrio e o acesso a uma qualidade de vida mais digna.

Deduz-se um novo desafio ambiental que é tratar a natureza como a principal riqueza da humanidade e que a agricultura tome o papel do agronegócio, buscando superar qualquer atraso em relação ao setor industrial, com uma integração do sistema econômico e um melhor atendimento público as necessidades agrícolas.

Verificar-se a importância da busca pela justiça e pela igualdade na atual sociedade de consumo, na qual todos estão inseridos, de modo a ser tanto consumidor quanto mercadoria. Constata-se que o maior problema é a desigualdade em todas as áreas e esta decorre da injustiça e da falta de aplicação das normas já existentes.

Pode-se dizer que o direito alimentar no Protocolo de Nagoya está não só garantido explicitamente em várias partes como foi mencionado, mas implicitamente também traria boa repercussão para este direito se o Brasil o ratifica-se.

Conclui-se que com a ratificação do Protocolo de Nagoya, não apenas o Direito à Alimentação estaria garantido, como também a proteção de toda a diversidade biológica que é imprescindível para uma sadia qualidade de vida de todos os seres humanos. Os direitos sobre os recursos de cada país estariam mais protegidos e haveria maior transparência nas negociações. Bem como, os conhecimentos de cada povo estariam preservados, sempre com uma justa e equitativa repartição de benefícios. 


\section{REFERÊNCIAS BIBLIOGRÁFICAS}

ANTUNES, Paulo de Bessa. Direito Ambiental. São Paulo: Atlas, 2015.

BAUMAN, Zygmunt. Vidas desperdiçadas. Tradução Carlos Alberto Medeiros. Rio de Janeiro: Jorge Zahar Ed., 2005.

. Modernidade líquida. Tradução Plínio Dentzien. Rio de Janeiro: Zahar, 2001. Disponível em: <https://books.google.com.br/books?id=CbMd0xJoI18C\&pg=PA4\&hl=ptBR\&source=gbs_selected_pages\&cad=2\#v=onepage \&q\&f=false> Acessado em: 30/08/2016.

\section{BRASIL. Constituição Federal de 1988.}

BRASIL. Decreto $n^{\circ} 591$ de 06 de julho de 1992. Pacto Internacional de Direitos Econômicos, Sociais e Culturais.

BRASIL. Ministério do Meio Ambiente - MMA. Convenção sobre Diversidade Biológica (CDB). Cópia do Decreto Legislativo n. 2, de 05 de junho de 1992. Brasília - DF, 2000. Disponível em: <http://www.mma.gov.br/estruturas/sbf_dpg/_arquivos/cdbport.pdf> Acessado em: 09/08/2016.

CARSON, Rachel. Primavera Silenciosa. Tradução Claudia Sant’Ana Martins. São Paulo: Gaia, 2010.

CASTRO, José de. Geografia da fome: o dilema brasileiro - pão ou aço. $4^{\circ}$ ed. Rio de Janeiro. Civilização brasileira, 1984.

COSTA, Alexandre Bernardino. Desafios da teoria do poder constituinte no Estado democrático de Direito. Tese de doutorado em direito pela Universidade Federal de Minas Gerais, 2005.

GONÇALVES, Carlos Walter Porto. "Geografia da riqueza, fome e meio ambiente: pequena contribuição crítica ao atual modelo agrário/agrícola de uso dos recursos naturais." Revista Internacional Interdisciplinar INTERthesis, 2004.

GUSTIN, Miracy Barbosa de Sousa; DIAS, Maria Tereza da Fonseca. (Re)pensando a pesquisa jurídica: teoria e prática. Belo Horizonte: Del Rey, 2010. 
HABERMAS, Jürgen. Estado democrático de Direito: uma amarração paradoxal de princípios contraditórios? In: HABERMAS, J. Era das transições. Tradução e introdução de Flávio Siebeneichler. - Rio de Janeiro: Tempo Brasileiro. 2003.

MACHADO, Luiz Carlos Pinheiro e MACHADO FILHO, Luiz Carlos Pinheiro. A dialética da agroecologia: contribuições para um mundo com alimentos sem veneno. São Paulo: Expressão Popular, 2014.

MOONEY, Patrick Roy. O Escândalo das Sementes: o Domínio na Produção de Alimentos. São Paulo: Nobel, 1987.

ONU. Declaração Universal dos Direitos Humanos. Resolução nº 217 A (III) da Assembleia Geral das Nações Unidas, 1948. (CDB). Disponível em: $<$ http://www.direitoshumanos.usp.br/index.php/Declara\%C3\%A7\%C3\%A3o-Universal-dos-DireitosHumanos/declaracao-universal-dos-direitos-humanos.html>. Acessado em: 06/08/2016.

ROCHA, Eduardo Gonçalves. Direito à Alimentação: teoria constitucional-democrática e políticas públicas. São Paulo: LTr, 2011.

SECRETARIADO DA CONVENÇÃO SOBRE DIVERSIDADE BIOLÓGICA; MINISTÉRIO DO MEIO AMBIENTE (MMA). Protocolo de Nagoya sobre acesso a recursos genéticos e repartição justa dos benefícios derivados de sua utilização à Convenção sobre Diversidade Biológica. Brasilia: MMA, 2014.

SHIVA, Vandana. Biopirataria: a pilhagem da natureza e do conhecimento. Petrópolis: Vozes, 2001.

VALENTE, Flavio Luiz Schieck. Direito humano à alimentação: desafios e conquistas. São Paulo: Cortez editora, 2002.

ZIEGLER, Jean. Destruição em massa: Geopolítica da fome. Tradução e prefácio de José Paulo Netto, $1^{\circ}$ ed. São Paulo: Cortez, 2013. 